BRIEF COMMUNICATION OPEN

\title{
An innovative COPD early detection programme in general practice: evaluating barriers to implementation
}

\author{
This article has been corrected since publication and a corrigendum has also been published
}

Joseph AM Dirven ${ }^{1}$, Albine Moser ${ }^{1}$, Huibert J Tange ${ }^{1}$, Jean WM Muris ${ }^{1}$ and Onno CP van Schayck ${ }^{1}$

In the Netherlands an innovative programme for early detection of chronic obstructive pulmonary disease (COPD) in primary care among patients aged 40-70 years has been evaluated in both an effect study and a pilot implementation study. Health-care providers identified four obstacles for successful implementation of a COPD early detection programme. This Brief Communication describes the most important results of a qualitative study using in-depth interviews.

npj Primary Care Respiratory Medicine (2014) 24, 14055; doi:10.1038/npjpcrm.2014.55; published online 28 August 2014

The Dutch programme for early detection of chronic obstructive pulmonary disease (COPD) in primary care among patients aged 40-70 years consists of the Respiratory Health Screening Questionnaire $^{1}$ followed by spirometry. The effect study ${ }^{2}$ showed that this approach would lead to $20 \%$ more known COPD cases in Dutch general practices, and the implementation study ${ }^{3}$ showed that it was feasible for general practices to adopt this programme. However, a validated written questionnaire among five clusters of 39 health-care professionals ${ }^{4}$ also identified four potential obstacles for success: two perceived barriers were related to the provider (need for assistance and financial compensation). The two others were related to the patient (socio-economic status (SES) and ethnicity) (Table 1). The format of Table 1 is based on Peters et al. ${ }^{4}$ the contents of Table 1 are based on Dirven et al. ${ }^{3}$ As the Dutch College of General Practitioners to implement this programme nation-wide, it is important to have more insight into these barriers, so we explored them in depth in a qualitative study. We conducted semistructured face-to-face interviews ${ }^{5}$ with five doctors and four practice nurses who were involved in the already-mentioned implementation study. ${ }^{3}$ The interviews were audiotaped and parsed through directed content analysis. ${ }^{6}$ In this Brief Communication we share the results of this unpublished study.

\section{PROVIDER-BOUND BARRIERS: WORKLOAD AND FINANCIAL COMPENSATION}

Health-care providers were confident of having enough knowledge to work out preventive activities, but expressed their need for a work-up protocol to follow the consecutive steps of the programme and for helpdesk support. Most of them perceived preventive activities as a challenging task and as an intrinsic part of their responsibility. Contracting out COPD prevention was no option. They considered COPD early detection as part of a stepwise integrated care approach next to other activities such as case finding. If revenues would remain low, however, they feared that the burden of extra effort and stress to reach programme deadlines over a longer period might cause feelings of frustration among health-care providers. They preferred a 5-yearly early detection programme, in which activities are concentrated in
3-6 months. They wished to be facilitated by receiving information in advance about current and expected new COPD cases, expected patient response, revenue, workload, cost and financial compensation. Extra workload should be accompanied by an increase in supportive staff and should be financially compensated. Some respondents expected that such measures would work as a stimulus for adopting the programme. Others were not certain if the programme would be reimbursed, since health-care insurance companies take the position that preventive activities in primary care should not be compensated. Yet, most interviewed doctors prompted that general practices are the most appropriate place for implementation of the early-detection programme, because all required facilities are available (such as rooms, tools and instruments). Practice nurses perceived potential barriers among the administrative procedures, such as customising invitational letters and administering questionnaires with login codes and registration numbers. Other inconvenient experiences were ill-timed over-the-desk question handling and unplanned efforts to persuade patients to have spirometry.

\section{PATIENT-BOUND BARRIERS: SOCIOECONOMIC STATUS (SES) AND ETHNICITY}

Health-care providers felt that patients basically appreciated earlydetection activities. Their perceptions of non-compliant behaviour among low-SES patients, however, varied. Providers from practices with predominantly moderate and high-SES patients showed more scepticism and doubt about the return on investment of the programme for low-SES patients. They noticed less compliance from this group, while investing more time with them for explanation and counselling. Providers from practices with predominantly low-SES patients, on the other hand, were less pessimistic and showed more compassion regarding this low compliance. They were more motivated and creative in finding alternative ways to keep these patients aboard. Providers of moderate-high SES practices other than these of low-SES practices stated that their low-SES patients 'don't show up'; 'are often very difficult to deal with'; 'say yes and do no'; and 'are difficult to treat because they refer to their unhealthy peer group'. Such statements suggest that doctors in

\footnotetext{
${ }^{1}$ Caphri School of Public Health and Primary Care-Department of General Practice, Maastricht, The Netherlands.

Correspondence: JAM Dirven (jos.dirven@maastrichtuniversity.nl)

Received 1 March 2014; revised 26 June 2014; accepted 13 July 2014 
Table 1. Barriers and Facilitators Assessment Instrument

\begin{tabular}{|c|c|c|}
\hline Domain & & Aspect \\
\hline \multicolumn{3}{|c|}{ Innovation characteristics } \\
\hline 1 & Innovation & Compatibility \\
\hline 2 & Innovation & Time investment \\
\hline 3 & Innovation & Specificity/sensitivity \\
\hline 4 & Innovation & Didactic benefit \\
\hline 5 & Innovation & Attractiveness \\
\hline \multicolumn{3}{|c|}{ Care provider characteristics } \\
\hline 6 & Care provider & Attitude/roll perception \\
\hline 7 & Care provider & Knowledge motivation \\
\hline 8 & Care provider & Doubts innovation \\
\hline 9 & Care provider & Life/working style \\
\hline 10 & Care provider & Education \\
\hline 11 & Care provider & Involvement \\
\hline \multicolumn{3}{|c|}{ Patient characteristics } \\
\hline 12 & Patient & Age \\
\hline 13 & Patient & Ethnicity \\
\hline 14 & Patient & Financial situation/SES \\
\hline 15 & Patient & Number patient contacts \\
\hline 16 & Patient & Health status \\
\hline 17 & Patient & Motivation to change \\
\hline \multicolumn{3}{|c|}{ Context characteristics } \\
\hline 18 & Context & Group norms/socialisation \\
\hline 19 & Context & Reimbursement/ insurance system \\
\hline 20 & Context & Law/regulations \\
\hline 21 & Context & Opening hours of practice \\
\hline 22 & Context & Supporting staff \\
\hline 23 & Context & Facilities \\
\hline 24 & Context & Practice building \\
\hline \multicolumn{3}{|c|}{$\begin{array}{l}\text { In gray: significant barriers indicated by the responding health-care } \\
\text { providers. } \\
\text { Abbreviation: SES, socioeconomic status. }\end{array}$} \\
\hline
\end{tabular}

moderate-high-SES practices have lower outcome expectancy and lower self-efficacy towards low-SES patients than doctors in low-SES practices. This is a reason for concern, as when a physician does not believe that a recommendation will lead to an improved outcome (s)he will be less likely to adhere to the guideline. ${ }^{7}$ Within the group of low-SES patients, heavy smokers were considered the most reluctant to respond to the programme, although these patients appeared to be aware of the bad consequences of smoking. Some health-care providers explained this reluctance by the suggestion that heavy smokers were inclined to lose self-confidence and assume a victim role. Care providers commented on low-SES smokers as a separate risk group because 'they have been more reluctant to show up', while contrastingly 'they like to learn about their health status'. Low-SES doctors, other than moderate-high-SES doctors, mentioned they felt commitment to deal with this specific group. All care providers were proposing that low-SES smokers show 'a frail motivation to quit smoking' and also that 'their motivation decreases in case of lesser complaints or symptoms'. Care providers think that low-SES smokers seem to be well aware of the bad consequences of smoking because 'they think they even will die because of this'. Most of them are also aware of 'not being able to quit and think they fail when they are not successful in quitting smoking'. Providers proposed 'they rather choose the victim role than quit smoking and subsequently refrain from practice visits because of feeling guilty'. In literature we can find similar statements: 'Current smokers feel ashamed and guilty about their disapproved lifestyle where social exclusion increases defensive actions and no show'.8 Subsequently, doctors proposed to refrain from short separate quit smoking warnings during consultations. It was observed that compliance problems accumulated among ethnic patients, due to the frequent combination of low SES, heavy smoking and low literacy. There were doctors who suggested treating this whole group as high risk for COPD, recommending direct spirometry testing without the preceding questionnaire.

To the best of our knowledge no such studies as the one presented here and the ones published earlier in this Journal ${ }^{2,3}$ have been published before. Therefore it is difficult to compare different implementation strategies of early detection of COPD in the Netherlands with other countries. However, we believe that this subject is highly relevant, also in countries with developing economies. Especially in the latter countries we know that the exposure to indoor pollution due to the use of biomass fuel is leading to high incidences of COPD in women. ${ }^{9-11}$

\section{Conclusion}

Although it has been demonstrated that an early detection programme for COPD in primary care is feasible and effective, it is not a guarantee for successful implementation. Our study shows that qualitative exploration of experiences from a pilot implementation yields valuable information about barriers that may hamper its introduction or flaw its effect. We suggest that policymakers take into consideration the solutions brought forward by the interviewees in our study.

\section{COMPETING INTERESTS}

The authors declare no conflict of interest.

\section{FUNDING}

The authors declare that no funding was received.

\section{REFERENCES}

1 Schayck CP, van Halbert RJ, Nordyke RJ, Isonaka S, Maroni J, Nonikov D. Comparison of existing symptom-based questionnaires for identifying COPD in the general practice setting. Respirology 2005; 10: 323-333.

2 Dirven JA, Tange HJ, Muris JW, van Haaren KM, Vink G, van Schayck OC. Early detection of COPD in general practice: patient or practice managed? A randomised controlled trial of two strategies in different socioeconomic environments. Prim Care Respir J 2013; 22: 331-337.

3 Dirven Joseph AM, Tange Huibert J, Muris Jean WM, van Haaren Karin MA, Vink Gerrit, Onno CP et al. Early detection of COPD in general practice: implementation, workload and socioeconomic status. A mixed methods observational study. Prim Care Respir J 2013; 22: 338-343.

4 Peters MAJ, Harmsen M, Laurant MGH, Wensing M. Room for Improvement? Barriers to and Facilitators for Improvement of Patient Care. Centre for Quality of Care Research (WOK), Radboud University Nijmegen Medical Centre: Nijmegen, 2002.

5 Rabionet SE. How I learned to design and conduct semi-structured interviews: an ongoing and continuous journey. Qual Rep 2011; 16: 563-566.

6 Hsieh HF, Shannon SE. Three approaches to qualitative content analysis. Qual Health Res 2005; 15: 1277-1288.

7 Bandura A. Social Foundations of Thought and Action: A Social Cognitive Theory. Prentice-Hall: Englewood Cliffs, NJ, USA, 1986.

8 Lindqvist G, Hallberg LRM. Feelings of guilt due to self-inflicted disease: a grounded theory of suffering from chronic obstructive pulmonary disease (COPD). J Health Psychol 2010; 15: 456-466.

9 Salvi S, Barnes PJ. Is exposure to biomass smoke the biggest risk factor for COPD globally? Chest 2010; 138: 3-6.

10 Kurmi OP, Lam KB, Ayres JG. Indoor air pollution and the lung in low- and medium-income countries. Eur Respir J 2012; 40: 239-254.

11 World Health Organization. Fuel for life-household energy and health. World Health Organization, 2006. http://www.who.in1/indoorair/publications/fuelforlife.pdf.

This work is licensed under a Creative Commons AttributionNonCommercial-ShareAlike 4.0 International License. The images or other third party material in this article are included in the article's Creative Commons license, unless indicated otherwise in the credit line; if the material is not included under the Creative Commons license, users will need to obtain permission from the license holder to reproduce the material. To view a copy of this license, visit http:// creativecommons.org/licenses/by-nc-sa/4.0/ 